\title{
Different involvement of type 1, 2, and 3 ryanodine receptors in memory processes
}

\author{
Nicoletta Galeotti, ${ }^{1,3}$ Alessandro Quattrone, ${ }^{2}$ Elisa Vivoli, ${ }^{1}$ Monica Norcini, ${ }^{1}$ \\ Alessandro Bartolini, ${ }^{1}$ and Carla Ghelardini ${ }^{1}$ \\ ${ }^{1}$ Department of Preclinical and Clinical Pharmacology, University of Florence, I-50139 Florence, Italy; ${ }^{2}$ Laboratory of Magnetic \\ Resonance Center and FiorGen Foundation, University of Florence, 50019 Florence, Italy
}

\begin{abstract}
The administration of the ryanodine receptor (RyR) agonist 4-Cmc $(0.003-9 \mathrm{nmol}$ per mouse intracerebroventricularly [i.c.v.]) ameliorated memory functions, whereas the RyR antagonist ryanodine $(0.0001-1$ nmol per mouse i.c.v.) induced amnesia in the mouse passive avoidance test. The role of the type 1, 2, and 3 RyR isoforms in memory processes was then evaluated by inhibiting the expression of the three RyR proteins in the mouse brain. A selective knockdown of the RyR isoforms was obtained by the i.c.v. administration of antisense oligonucleotides (aODNs) complementary to the sequence of RyR1, RyR2 and RyR3 proteins, as demonstrated by immunoblotting experiments. RyR1 (5-9 nmol per mouse i.c.v.) knockdown mice did not show any memory dysfunction. Conversely, RyR2 (1-7 nmol per mouse i.c.v.) and RyR3 (1-7 nmol per mouse i.c.v.) knockdown animals showed an impairment of memory processes. This detrimental effect was temporary and reversible, disappearing $7 \mathrm{~d}$ after the end of the aODN treatment. At the highest effective doses, none of the compounds used impaired motor coordination, as revealed by the rota rod test, nor modified spontaneous mobility and inspection activity, as revealed by the hole-board test. In conclusion, the lack of any involvement of cerebral RyR1 was demonstrated. These findings also showed the involvement of type 2 and type 3 RyR in the modulation of memory functions identifying these cerebral RyR isoforms as critical targets underlying memory processes.
\end{abstract}

An increase in cytoplasmic $\mathrm{Ca}^{2+}$ in hippocampal neurons plays an important role in the regulation of neuronal processes, including synaptic transmission and synaptic plasticity such as longterm potentiation (LTP) and long-term depression (Nishiyama et al. 2000; Balkowiec and Katz 2002). It has also been proposed that altered $\mathrm{Ca}^{2+}$ regulation might play a role in brain aging and Alzheimer's disease (Gibson and Peterson 1987; Landfield 1987; Khachaturian 1989; Disterhoft et al. 1994). In brain neurons from aging rodents and rabbits, as compared with neurons from younger animals, $\mathrm{Ca}^{2+}$ influx associated with action potentials induces a larger $\mathrm{Ca}^{2+}$-dependent afterhyperpolarization (AHP) (Landfield and Pitler 1984; Moyer et al. 1992; Potier et al. 1992; Disterhoft et al. 2004; Stutzmann et al. 2006) and impairs shortterm synaptic plasticity (Landfield et al. 1986; Thibault et al. 2001). Furthermore, these findings have been reinforced by studies showing that pharmacologically isolated $\mathrm{Ca}^{2+}$ action potentials (Pitler and Landfield 1990; Disterhoft et al. 1996), whole-cell $\mathrm{Ca}^{2+}$ currents (Campbell et al. 1996), and $\mathrm{Ca}^{2+}$ transients during repetitive spike trains also are larger in hippocampal neurons from aged animals (Thibault et al. 2001; Hemond and Jaffe 2005). An apparent excess $\mathrm{Ca}^{2+}$ influx via L-type voltage-gated $\mathrm{Ca}^{2+}$ channels (L-VGCC) appears to be involved in this $\mathrm{Ca}^{2+}$ dysregulation (Landfield 1996; Thibault et al. 1998).

In addition to the accumulating evidence of increased $\mathrm{Ca}^{2+}$ influx through L-VGCCs, there is also recent evidence that altered function of intracellular organelles might play a critical role in $\mathrm{Ca}^{2+}$ regulation during aging or Alzheimer's disease (Toescu and Verkhratsky 2003). In particular, changes in intracellular $\mathrm{Ca}^{2+}$ release from the endoplasmic reticulum appear likely to contribute to brain $\mathrm{Ca}^{2+}$ dyshomeostasis and have been associated with changes in $\left[\mathrm{Ca}^{2+}\right]$ i.

\footnotetext{
${ }^{3}$ Corresponding author.
}

E-mail nicoletta.galeotti@unifi.it; fax 39-055-4271280.

Article is online at http://www.learnmem.org/cgi/doi/10.1101//m.929008.
During neuronal activation, one important feature of $\mathrm{Ca}^{2+}$ signaling is the release of intracellular $\mathrm{Ca}^{2+}$ stores as a consequence of $\mathrm{Ca}^{2+}$ influx through voltage- or ligand-gated $\mathrm{Ca}^{2+}$ channels, the $\mathrm{Ca}^{2+}$-induced $\mathrm{Ca}^{2+}$ release (CICR) (Tully and Treistman 2004). The mechanism through which CICR occurs is by activation of ryanodine receptors (RyR), one of the two $\mathrm{Ca}^{2+}$ release channels found on the endoplasmic reticulum.

RyRs are widely expressed in mammalian brain (Giannini et al. 1995), where they play a central role in the regulation of intracellular calcium homeostasis (Simpson et al. 1995). RyRs regulate vital brain functions, including protein synthesis (Paschen et al. 1996), neurotransmitter release (Mothet et al. 1998; He et al. 2000), action potential hyperpolarization (Kawai and Watanabe 1989), and axonal retrograde transport (Breuer et al. 1992).

These receptors localize in the endoplasmic reticulum in the cell soma, dendrites, dendritic spines, and synaptic terminals (Sharp et al. 1993). Three main isoforms of the receptor (RyR1, RyR2, and RyR3) are present in brain, the RyR2 being predominant (Zalk et al. 2007). To date little is known on the role of the three neuronal RyR isoforms from behavioral studies. The aim of the present study was to investigate the involvement of RyR1, RyR2, and RyR3 in the intracellular mechanism involved in memory processes in a mouse passive avoidance task. To this purpose, we selectively inhibited the expression of each RyR subtype by using antisense oligonucleotides.

\section{Results}

Effect of RyR pharmacological modulators on memory processes

The RyR agonist 4-chloro- $m$-cresol (4-Cmc; 0.003-9 nmol per mouse intracerebroventricularly [i.c.v.], administered $30 \mathrm{~min}$ before the training session) increased the latency to enter the dark 
compartment in the retention session of the mouse passive avoidance test. The ANOVA on the retention session latencies revealed a significant group effect $\left(\mathrm{F}_{(8,162)}=4.506 ; P<0.0001\right)$. Bonferroni/Dunn multiple comparison analysis showed that mice receiving either $0.03(P<0.05)$ or $0.3 \mathrm{nmol}(P<0.05)$ per mouse i.c.v. of 4 -Cmc spent significantly more time to enter the dark compartment than controls. (Fig. 1A). In these experimental conditions, diphenhydramine ( $20 \mathrm{mg} / \mathrm{kg}$ intraperitoneally [i.p.]) and clonidine $(0.125 \mathrm{mg} / \mathrm{kg}$ i.p.), used as reference drugs, produced a statistically significant amnesic effect $(P<0.05$ vs. control group) (Fig. 1A). Time course experiments on 4-Cmc $(0.03$ nmol per mouse) revealed an overall significant difference between groups $\left(F_{(4,75)}=4.286 ; P<0.001\right)$. Bonferroni/Dunn multiple comparison analysis showed that a significant 4-Cmcinduced ameliorating effect on memory functions was obtained when administered 30 min before the training session $(P<0.05)$ (Fig. 1B).

The RyR antagonist ryanodine $(0.01-1$ nmol per mouse i.c.v.) was devoid of any effect when injected 15 min before the training session, as illustrated in Figure 2A. When administered immediately after the training session, an amnesic effect was obtained. The ANOVA on the retention session latencies revealed a

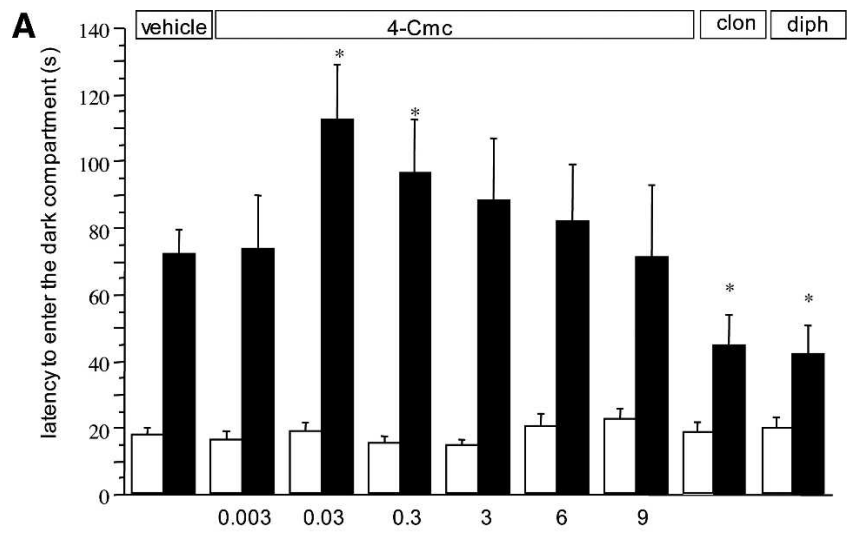

B

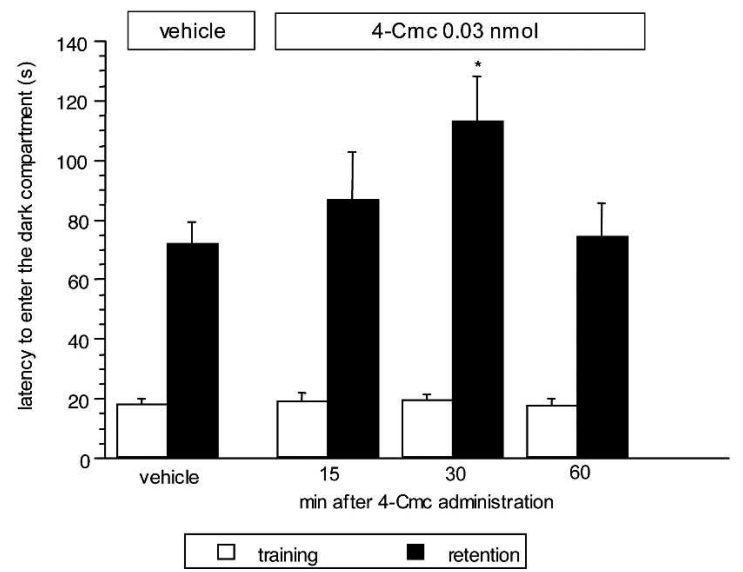

Figure 1. (A) Dose-response curve of $4-\mathrm{Cmc}$ in the mouse passive avoidance test. $4-\mathrm{Cmc}(0.003-9 \mathrm{nmol}$ per mouse i.c.v. $)$ was administered 30 min before the training session. Data are expressed as mean \pm SEM; ${ }^{*} P<0.05$ in comparison with vehicle-treated mice. (Vehicle) Ethanol $0.5 \%$; (clon) clonidine $0.125 \mathrm{mg} / \mathrm{kg}$ i.p.; (diph) diphenhydramine 20 $\mathrm{mg} / \mathrm{kg}$ i.p. (B) Time-course curve of $4-\mathrm{Cmc}$ in the mouse passive avoidance test. $4-\mathrm{Cmc}(0.03 \mathrm{nmol}$ per mouse i.c.v.) was administered 15, 30, or $60 \mathrm{~min}$ before and immediately after the training session. Data are expressed as mean \pm SEM; ${ }^{*} P<0.05$ in comparison with vehicle-treated mice. (Vehicle) Ethanol $0.5 \%$
A

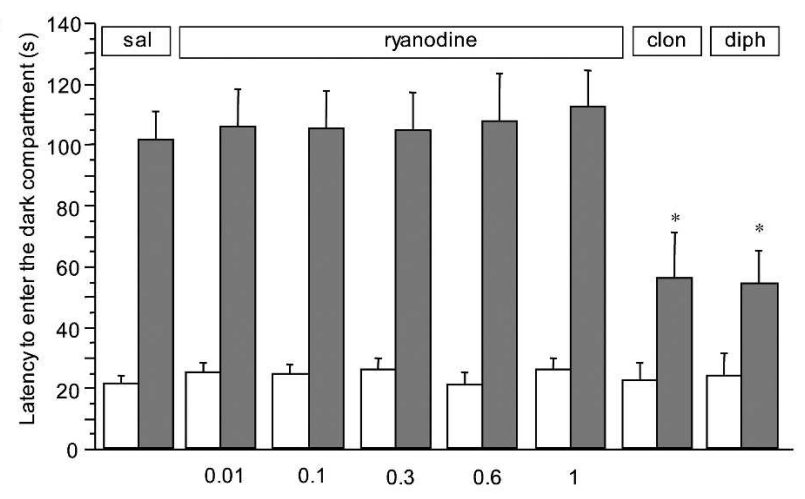

B

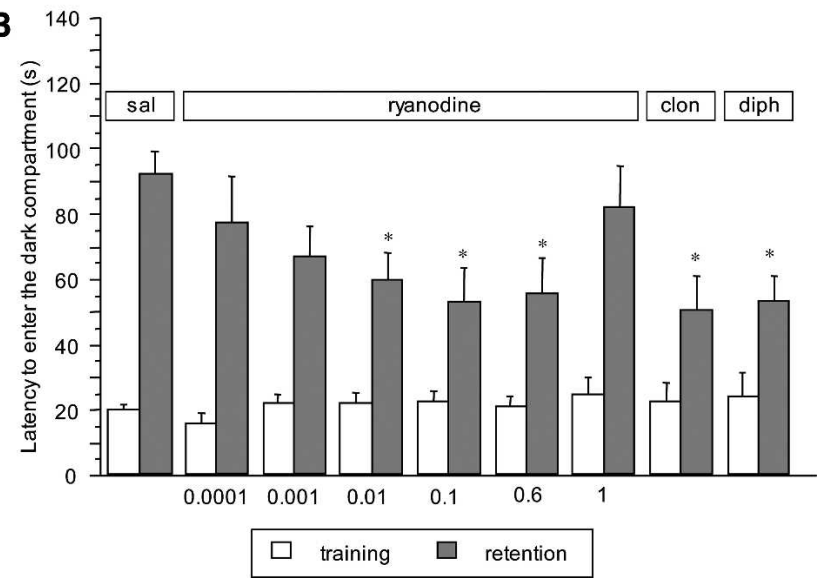

Figure 2. (A) Lack of effect of ryanodine in the mouse passive avoidance test. Ryanodine (0.01-1 nmol per mouse i.c.v.) was administered 15 min before the training session. Data are expressed as mean \pm SEM; ${ }^{*} P<0.05$ in comparison with saline-treated mice; (clon) clonidine 0.125 $\mathrm{mg} / \mathrm{kg}$ i.p.; (diph) diphenhydramine $20 \mathrm{mg} / \mathrm{kg}$ i.p. (B) Dose-response curve of the amnesic effect of ryanodine in the mouse passive avoidance test. Ryanodine (0.0001-1 nmol per mouse i.c.v.) was administered immediately after the training session. Data are expressed as mean \pm SEM; $* P<0.05$ in comparison with vehicle-treated mice; (clon) clonidine 0.125 $\mathrm{mg} / \mathrm{kg}$ i.p.; (diph) diphenhydramine $20 \mathrm{mg} / \mathrm{kg}$ i.p.

significant group effect $\left(F_{(7,135)}=3.954 ; P<0.001\right)$. Bonferroni/ Dunn multiple comparison analysis showed that mice receiving $0.01(P<0.05), 0.1(P<0.05)$ or $0.6 \mathrm{nmol}(P<0.05)$ per mouse i.c.v. of ryanodine spent significantly less time to enter the dark compartment than controls. The intensity of the amnesia obtained was comparable to that induced by clonidine $(0.125 \mathrm{mg} /$ $\mathrm{kg}$ i.p.) and diphenhydramine (20 mg/kg i.p.) (Fig. 2B).

The amnesia induced by ryanodine $(0.1 \mathrm{nmol}$ per mouse i.c.v. injected immediately after the training session) was prevented by 4 -Cmc (injected $30 \mathrm{~min}$ before the training session) coadministration $\left(F_{(5,109)}=3.941 ; P<0.01\right)$. Bonferroni/Dunn multiple comparison analysis confirmed the RyR-mediated mechanism of ryanodine-induced amnesia. Indeed, the detrimental effect of ryanodine was prevented by pretreatment with $4-\mathrm{Cmc}$ at the dose of 9 nmol per mouse $(P<0.05)$ (Fig. 3). Both 4 -Cmc concentrations used were ineffective when injected alone (Fig. 3).

4-Cmc and ryanodine did not alter the latency to enter the dark compartment in the training session in comparison with control groups as shown in Figures 1, 2, and 3.

\section{Role of type 1, 2, and 3 RyR in memory processes}

Pretreatment with an aODN against type 1 RyR (5-9 nnmol per mouse i.c.v.) did not modify the entrance latency in the dark 


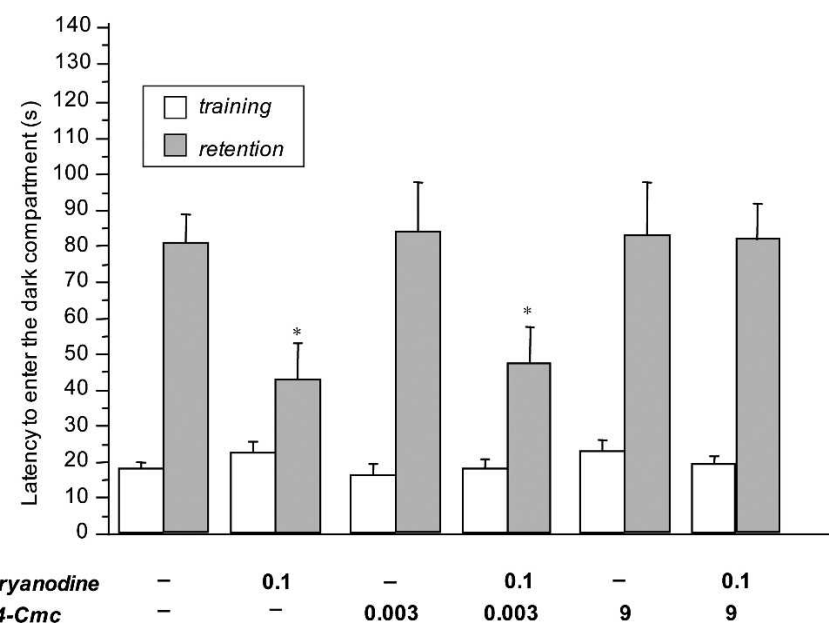

Figure 3. Reversal by $4-\mathrm{Cmc}$ of the amnesia induced by ryanodine in the mouse passive avoidance test. Doses administered (nmol per mouse i.c.v.) are reported below each column. 4-Cmc and ryanodine were injected 30 min before and immediately after the training session, respectively. Data are expressed as mean \pm SEM; ${ }^{*} P<0.05$ in comparison with saline-treated mice.

compartment in comparison with dODN treated mice. In the same experimental conditions clonidine $(0.125 \mathrm{mg} / \mathrm{kg}$ i.p. $)$ was able to induce amnesia $\left(F_{(4,85)}=3.908 ; P<0.01\right)$ (Fig. 4 A).

Knockdown of the type 2 RyR produced a detrimental effect on memory processes. The ANOVA on the retention session latencies revealed a significant group effect $\left(F_{(4,80)}=5.141\right.$; $P<0.001)$. Bonferroni/Dunn multiple comparison analysis showed that mice receiving $7 \mathrm{nmol}$ per mouse i.c.v. showed a significant lower latency to enter the dark compartment in comparison with dODN group $(P<0.05)$. The reduction of the entrance latency in the retention session was of intensity comparable to that produced by clonidine (Fig. 4B). Similarly, the knockdown of the type 3 RyR produced a detrimental effect on memory functions $\left(F_{(4,83)}=5.468 ; P<0.001\right)$ reaching the statistical significance at $7 \mathrm{nmol}$ per mouse i.c.v. (Bonferroni/Dunn multiple comparison analysis: $P<0.05$ ), as illustrated in Figure 4C.

Anti-RyR1, anti-RyR2, and anti-RyR3 did not modify the mouse entrance latency in the training session in comparison with the control groups (Fig. 4).

\section{Effect of aODNs on RyR1, RyR2, and RyR3 protein levels}

Mice were treated with the aODNs on day 1,2 , and 3 . On day 4 , $18 \mathrm{~h}$ after the last i.c.v. injection, mice were killed, and the cortex and hippocampus were dissected and examined for the protein levels of RyR1, RyR2, and RyR3 in comparison with mice treated with dODN using specific antisera developed against each RyR isoform. Figure 5A shows a representative immunoblot where three distinct prominent protein bands of $\sim 500 \mathrm{kDa}$ were observed, which display a tissue specificity of expression. The antiRyR1 antiserum selectivity was demonstrated by a specific interaction with RyR1 proteins present in the sarcoplasmic reticulum of skeletal muscle whereas the anti-RyR2 antiserum recognized the RyR2 proteins in cardiac muscle. RyR2 and RyR3 proteins were detected in all brain areas investigated. Conversely, RyR1 isoform was not detected in mouse cortex (Fig. 5A).

Densitometric analysis of all samples revealed a statistically significant reduction of the expression of RyR1 $(P<0.05$, Student's $t$-test $), \operatorname{RyR} 2\left(F_{(2,18)}=4.562 ; P<0.05\right)$ and RyR3 $\left(F_{(2,18)}=4.186 ; P<0.05\right)$ after aODN treatment at the highest concentration used (anti-RyR1 9 nmol i.c.v.; anti-RyR2 $7 \mathrm{nmol}$ i.c.v.; anti-RyR3 7 nmol i.c.v.) in comparison with mice treated with the corresponding dODN (Fig. 6B). Bonferroni/Dunn multiple comparison analysis confirmed that every aODN treatment decreased expression of the corresponding receptors in all cerebral areas investigated $(P<0.05)$ (Fig. 5B).

A dose-dependent influence on RyR expression in aODN treated animals as well as a correlation between degree of RyR subtype knockdown and severity of learning retrieval was observed. The dose of $1 \mathrm{nmol}$ per mouse of each aODN did not significantly reduce the corresponding RyR protein level and was devoid of any effect on learning processes. The dose of $5 \mathrm{nmol}$ per mouse reduced protein levels in anti-RyR1 $(82.0 \pm 6.8$, hippocampus), anti-RyR2 (76.7 \pm 6.9 , cortex; $73.1 \pm 7.6$ hippocampus), and anti-RyR3 (80.7 \pm 6.7 , cortex; $78.7 \pm 5.8$ hippocampus). This dose produced a reduction of the latency to enter the dark compartment in RyR2 and RyR3 knockdown mice that did not reach the statistical significance (Fig. 4B,C).
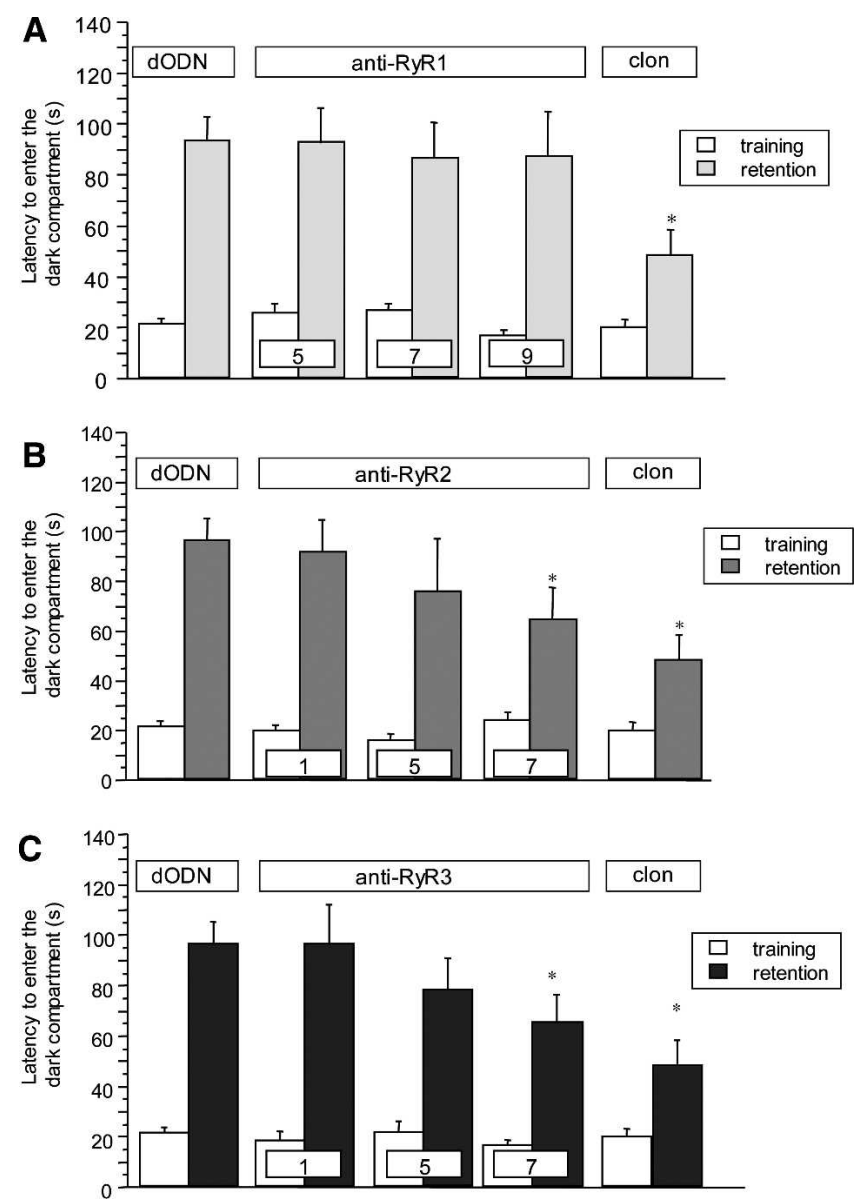

Figure 4. (A) Lack of effect of anti-RyR1 treatment (5-9 nmol per mouse i.c.v.) in the mouse passive avoidance test. Doses of anti-RyR1 administered (nmol per mouse i.c.v.) are reported in each column. Data are expressed as mean \pm SEM; ${ }^{*} P<<0.05$ in comparison with dODNtreated mice; (clon) clonidine $0.125 \mathrm{mg} / \mathrm{kg}$ i.p. (B) Dose-response curve of the amnesic effect of anti-RyR2 treatment (1-7 nmol per mouse i.c.v.) in the mouse passive avoidance test. Doses of anti-RyR2 administered (nmol per mouse i.c.v.) are reported in each column. Data are expressed as mean \pm SEM; ${ }^{*} P<0.05$ in comparison with dODN-treated mice; (clon) clonidine $0.125 \mathrm{mg} / \mathrm{kg}$ i.p. (C) Dose-response curve of the amnesic effect of anti-RyR3 treatment (1-7 nmol per mouse i.c.v.) in the mouse passive avoidance test. Doses of anti-RyR3 administered ( $\mathrm{nmol}$ per mouse i.c.v.) are reported in each column. Data are expressed as mean \pm SEM; ${ }^{*} P<0.05$ in comparison with dODN-treated mice; (clon) clonidine 0.125 $\mathrm{mg} / \mathrm{kg}$ i.p. 
A

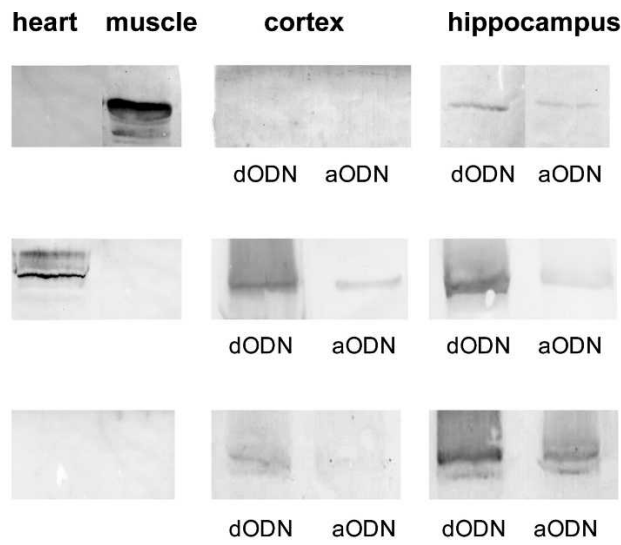

B

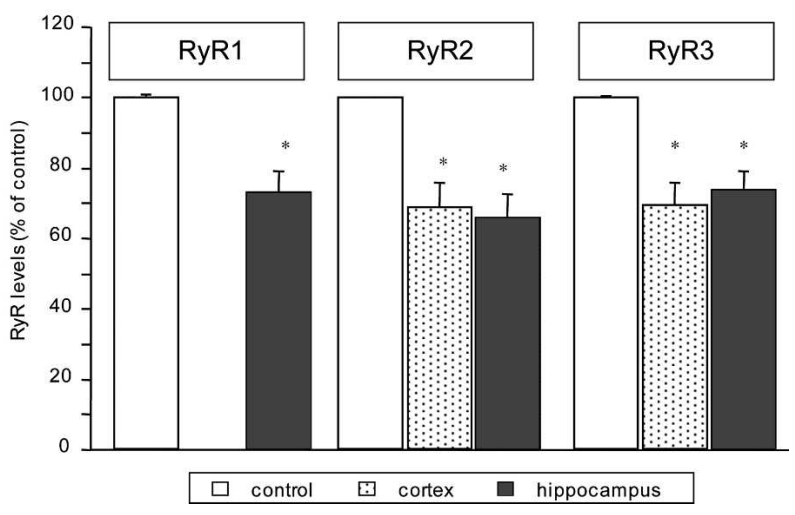

Figure 5. Reduction of RyR1, RyR2, and RyR3 protein expression in mouse muscle, heart, cortex, and hippocampus by aODN treament in comparison with corresponding dODN-treated mice. (A) Samples (100 $\mu \mathrm{g}$ protein/lane) of microsomal fractions of mouse cortex and hippocampus, and samples of heart ( $20 \mu \mathrm{g}$ protein/lane) and muscle ( $50 \mu \mathrm{g}$ protein/lane) were resolved on 6\% SDS-PAGE, transferred to nitrocellulose, and probed with RyR1, RyR2, or RyR3 antibody. (B) Densitometric quantitation of immunoreactive protein expressed relative to control. Data are expressed as mean \pm SEM of band intensities from each of the three groups ( $n=7$ per group). ${ }^{*} P<0.05$ vs. control.

The dODN did not significantly change the immunoreactivity when compared with that of naïve animals. Immunoprecipitation experiments also produced similar results (data not shown).

Immunoblots were reprobed for a protein considered to be not regulated as $\beta$-actin, and no significant density difference was revealed for this protein between samples from the RyR1, RyR2, and RyR3 downregulated brain region (data not shown).

Cross-reactivity of the primary antibodies used was excluded.

\section{Time-dependent reversibility of RyR protein knockdown and memory impairment}

To evaluate the reversibility of the aODN effects, mice were treated with the aODNs on days 1, 2, and 3; $7 \mathrm{~d}$ after the last i.c.v. injection, mice were killed, and the cortex and hippocampus were dissected and examined for the protein levels of RyR1, RyR2, and RyR3 in comparison with mice treated with dODN. Figure 6A shows a representative immunoblot where three distinct prominent protein bands of $\sim 500 \mathrm{kDa}$, corresponding to RyR1, RyR2, and RyR3, were observed in the mouse hippocampus and cortex, with the exception of the RyR1 isoform that was not detected in mouse cortex (Fig. 5A). RyR subtypes protein expression in aODN treated mice was similar to control animals in both brain regions.

A time-course of the amnesia obtained after aODN treatment was performed. The impairment of memory processes produced by anti-RyR2 and anti-RyR3 at the active dose $(7 \mathrm{nmol}$ per mouse i.c.v.) disappeared $7 \mathrm{~d}$ after the end of the aODN pretreatment (Fig. 6B). The anti-RyR1 treated group showed entrance latency values in the retention session comparable to control, anti-RyR2, and anti-RyR3 treated groups (Fig. 6B).

\section{Effect of RyR pharmacological modulators and aODNs on mouse behavior}

The spontaneous mobility and exploratory activity of mice pretreated with anti-RyR1 (9 nmol per mouse i.c.v.), anti-RyR2 (7 nmol per mouse i.c.v.), anti-RyR3 (7 nmol per mouse i.c.v.), ryanodine $(0.1 \mathrm{nmol}$ per mouse i.c.v.), and 4 -Cmc $(9 \mathrm{nmol}$ per mouse i.c.v.) was evaluated by using the hole-board test. Both parameters in all treated groups were not impaired when compared with that of control mice. In the same experimental conditions D-amphetamine ( $1 \mathrm{mg} / \mathrm{kg}$ i.p.), used as the reference drug, increased both spontaneous mobility $\left(F_{(6,77)}=4.343\right.$; $P<0.05)$ and exploratory activity $\left(F_{(6,77)}=3.998 ; P<0.05\right)$ (Fig. 7A,B).

The motor coordination of mice was unmodified by administration of the above-mentioned treatments as revealed by the rota rod test. The number of falls from the rotating rod was com-

\section{A}

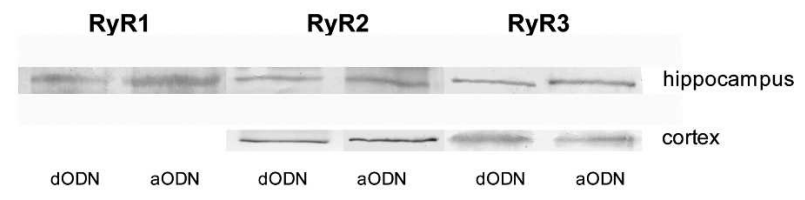

B

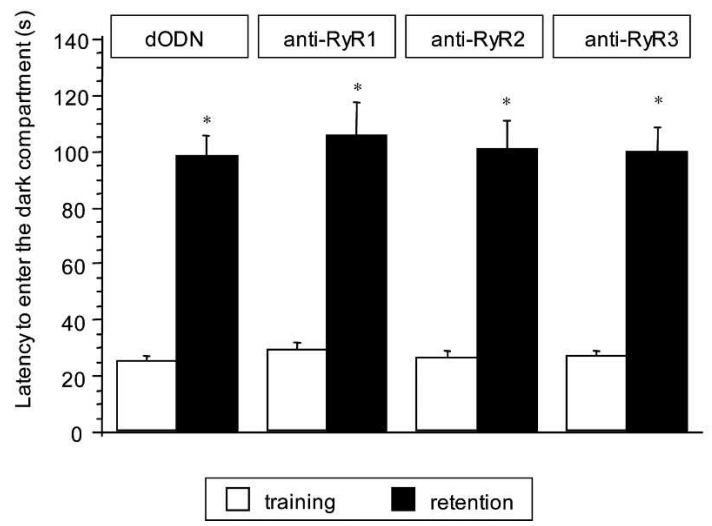

Figure 6. Reversibility of RyR1, RyR2, and RyR3 protein knockdown and memory impairment in aODN-treated mice in comparison with corresponding dODN-treated mice. (A) Samples $(100 \mu \mathrm{g}$ protein/lane) of microsomal fractions of mouse cortex and hippocampus were resolved on 6\% SDS-PAGE, transferred to nitrocellulose, and probed with RyR1, RyR2, or RyR3 antibody. (B) Lack of effect of anti-RyR1 ( $9 \mathrm{nmol}$ per mouse i.c.v.), anti-RyR2 $(7 \mathrm{nmol}$ per mouse i.c.v.), and anti-RyR3 (7 nmol per mouse i.c.v.) in the mouse passive avoidance test performed $7 \mathrm{~d}$ after the end of the aODN repeated treatment. Data are expressed as mean \pm SEM; ${ }^{*} P<0.05$ in comparison with the corresponding training session values (Student's $t$-test). 

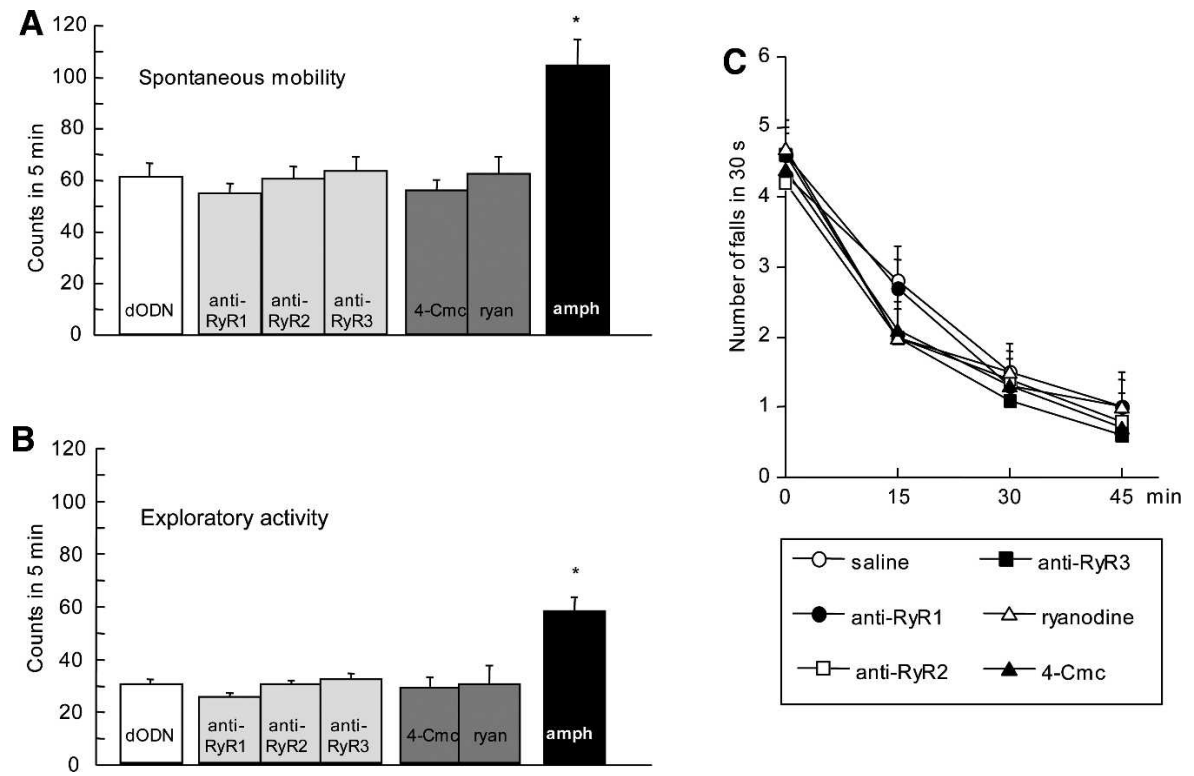

Figure 7. Lack of effect of anti-RyR1 ( $9 \mathrm{nmol}$ per mouse i.c.v.), anti-RyR2 (7 nmol per mouse i.c.v.), anti-RyR3 ( $7 \mathrm{nmol}$ per mouse i.c.v.), ryanodine $(0.1 \mathrm{nmol}$ per mouse i.c.v.), and $4-\mathrm{Cmc}(9 \mathrm{nmol}$ per mouse i.c.v.) on mouse spontaneous mobility $(A)$ and exploratory activity $(B)$ evaluated in the mouse hole board test, and on motor coordination (C) evaluated in the rota rod test. ODNs were administered once daily for $3 \mathrm{~d}$. The test was performed $18 \mathrm{~h}$ after the last injection. Amphetamine (amph) was administered at the dose of $1 \mathrm{mg} / \mathrm{kg}$ s.c.; data are expressed as mean $\pm \mathrm{SEM} ;{ }^{*} P<0.05 \mathrm{vs}$. control group.

parable with those of control mice at every session of the test (Fig. 7C).

\section{Discussion}

The role played by the three RyR isoforms in the modulation of memory processes is illustrated by these results. A different involvement of central RyR subtypes was demonstrated. In particular, the integrity and functionality of RyR2 and RyR3 proteins appears essential to avoid memory impairments. By contrast, the RyR1 subtype, in these experimental conditions, appears not to be involved.

The effect produced by ryanodine, a RyR pharmacological antagonist, was investigated in a mouse passive avoidance task. I.c.v. administration of ryanodine induced amnesia in mice. Neurons with pharmacologically reduced slow afterhyperpolarization currents (IsAHP) showed facilitated LTP. In particular, in peripheral neurons, a complete block of IsAHP was reported with ryanodine (Moore et al. 1998). However, in central neurons the involvement of RyRs in the reduction of IsAHP appears to be less evident. The CICR mechanism contributes less to the IsAHP (Kumar and Foster 2004; Van de Vrede et al. 2007) or does not participate to generation of IsAHP (Zhang et al. 1995). The ryanodine retention loss was observed only when the RyR antagonist was administered immediately after the training session. In accordance with our data, the RyR antagonist dantrolene produced a retention loss in chicks in a single trial passive avoidance task when administered immediately after training (Edwards and Rickard 2006). To confirm the role of RyRs in a mouse passive avoidance paradigm, the effect of 4-Cmc, a RyR agonist (Herrmann-Frank and Varsanyi 1993), was tested. 4-Cmc produced a dose-dependent ameliorating effect on memory processes demonstrated by an increase of the latency to enter the dark compartment in the retention session of the test. Conversely to ryanodine, this effect was obtained when 4 -CmC was administered $30 \mathrm{~min}$ before the training test.
This discrepancy can be explained considering that it has been observed that the antinociceptive (Galeotti et al. 2004b) and depressant-like (Galeotti et al. 2006) effects produced by $4-\mathrm{Cmc}$ became significant starting from $90 \mathrm{~min}$ after administration. Taking into account this latency to produce its pharmacological effects, the action of 4 -Cmc on memory processes might appear approximately in correspondence to the ryanodine effect. Since both RyR pharmacological modulators exerted their effect after the aversive stimulus of the training session was applied, we might hypothesize a possible action on retrieval rather than on the memory acquisition. However, given that $24 \mathrm{~h}$ are present between learning the task and recalling the task, any other mechanism cannot be excluded.

Ryanodine is a selective RyR antagonist unable to distinguish among RyR subtypes. To investigate the role played by the RyR isoforms, an antisense strategy was necessary since mice missing the RyR1 and RyR2 gene products die early during embryonic development. Mice carrying a targeted disruption of the RyR1 gene show complete loss of the skeletal muscle excitationcontraction coupling and die perinatally because of respiratory failure (Takeshima et al. 1995). Similar to what observed in RyR1 knockout mice, the generation of mice carrying a targeted disruption of the RyR2 gene indicates a pivotal role for the RyR2 isoform, not only in cardiac excitation-contraction coupling but also during myocardial development, as RyR2 knockout mice die at embryonic day 10 and show morphological abnormalities in the heart tub (Takeshima et al. 1998). These observations ruled out the possibility of using RyR1 and RyR2 knockout mice for behavioral studies. Mice lacking both RyR1 and RyR3 were also generated. These double-mutant mice did not actively move after birth and died, most probably from respiratory failure, as was the case for RyR1-deficient mice (Ikemoto et al. 1997)

RyRs are distributed not only in the central nervous system but also at a peripheral level. RyRs are present in the skeletal and cardiac muscle where their activation represents a crucial step for muscle contraction (Rossi and Sorrentino 2002). To avoid the possible appearance of peripheral effects that could lead to a misinterpretation of the results obtained, the aODNs used were administered directly into the cerebral ventricles.

The capability of the aODN treatment to knock down RyR protein levels was demonstrated by immunoblotting and immunoprecipitation experiments where the levels of RyR1, RyR2, and RyR3 from microsomes prepared from hippocampus and cortex of animals treated with the corresponding aODN, in comparison with the dODN-treated mice, were determined. A selective decrease of RyR1, RyR2, and RyR3 protein levels was demonstrated by using selective antibodies for each RyR isoform.

Knockdown of RyR2 produced memory disruption of intensity comparable to that induced by amnesic drugs such as the $\alpha 2$-adrenoceptor agonist clonidine (Galeotti et al. 2004a) and the antihistamine diphenhydramine (Galeotti et al. 2003), indicating the importance of the integrity and functionality of the type 2 RyR isoform for the memory processes in a mouse passive avoidance task. In agreement with our results, the importance of 
hippocampal microsomal RyR2 isoform in memory functions was postulated, since RyR2 mRNA and protein levels were upregulated in the hippocampus of rats intensely trained in a water maze (Zhao et al. 2000). Present results confirm and further extend the knowledge on the crucial role played by RyR 2 in the mnemonic functions.

To date, discrepant results on RyR3 involvement in memory were obtained by using RyR3 knockout mice. Futatsugi et al. (1999) noted improved spatial ability of RyR3 deficient mice. By contrast, Balshun et al. (1999) observed equivalent learning for both transgenic and wild-type animals. However, the transgenic mice demonstrated impaired ability to relearn a new target. We thought it necessary to investigate the RyR3 role by using a different experimental approach. We generated knockdown mice by using an antisense strategy. RyR3 knockdown animals showed memory impairment in the passive avoidance test demonstrated by a reduced latency to enter the dark compartment in the retention session of the test in comparison with the dODN-treated mice. In the present study, we demonstrated that the functionality of type 3 RyR is required for memory processing. In support to our results, Kouzu et al. (2000) reported that RyR3-deficient mice exhibited impairments of performance in the contextual fear conditioning test, passive avoidance test, and Y-maze learning test further confirming the role of RyR3 in memory functions. The reduction of expression of RyR3 by antisense treatment induced an amnesia of comparable intensity to that observed in anti-RyR2 treated mice and it appeared at the same concentrations. A similar involvement of these two receptor subtypes in memory functions in a mouse passive avoidance task can be postulated.

Conversely to anti-RyR2 and anti-RyR3 treated mice, RyR1 knockdown animals did not show any memory impairment in comparison with dODN-treated mice. The lack of effect of an aODN against RyR1 implies that this receptor subtype is not a major component of transduction mechanisms modulating memory functions. This observation represents the first investigation on the physiological role of cerebral RyR1. The lack of effect by the anti-RyR1 aODN in the mouse memory functions as a consequence to inefficient knockdown of the RyR1 protein by the antisense treatment can be ruled out. Western blotting and immunoprecipitation experiments revealed a reduction of the RyR1 protein levels with the highest dose administered of antiRyR1. The different role of the three RyR isoforms in memory processes might be due the different cerebral distribution of RyR1, RyR2, and RyR3. Type 2 RyR represents the predominant isoform in the central nervous system found in widespread brain regions (McPherson and Campbell 1993; Giannini et al. 1995). Type 3 RyR has also a wide cerebral distribution including areas involved in memory processes such as hippocampus and cortex. Conversely, RyR1 has a limited distribution being absent in the cortex, as demonstrated by immunoblotting experiments, and in agreement with literature data (Giannini et al. 1995).

aODNs transiently inactivate single genes down-regulating the synthesis of the encoded protein. The reversibility of the aODN effect is fundamental to ensure that the behavioral effects observed were related to the knockdown of the target protein. The memory disruption observed in anti-RyR2 and anti-RyR3 treated animals disappeared $7 \mathrm{~d}$ after pretreatment with the aODNs. This return of sensitivity implies both the total reversal of aODN-induced specific inhibition of RyR proteins and a lack of damage or toxicity associated with aODN treatment. Time-course experiments on RyR knockdown mice might also support the argument that acquisition and/or consolidation processes were not altered by the treatments given the reversal of the effect with time.

Pretreatment with aODNs at the highest effective doses did not modify the entrance latency in the training session, showing the absence of any unspecific effect produced by these pretreatments. This observation ruled out the possibility that the amnesic effect exerted by aODNs may have resulted from a sequenceindependent action on cerebral structures.

As RyRs are widely distributed in the neural areas, the function of a variety of cellular receptors might be altered by pharmacological modulators as well as by the impairing effect of the antisense treatment. It has been, therefore, necessary to evaluate the possible induction of side effects by ryanodine, 4 -Cmc, and the anti-RyR treatments. All compounds investigated did not modify animals' gross behavior. Additional behavioral tests were, then, performed to unmask any side effect produced by the treatments that cannot be revealed by the researcher through the observation of the animal's spontaneous behavior. In the passive avoidance test, an altered motor activity may shorten the latency to enter the dark compartment giving a false positive effect. The treatments did not impair motor coordination, as revealed by the progressive reduction of the number of falls in the rota rod test. The number of falls in this test progressively decreases since animals learn how to balance on the rotating rod. The lack of variation, or an increase in the number of falls after treatment, indicates an impairment of mice motor coordination that could lead to a misinterpretation of the results obtained in the behavioral test. Moreover, treatments did not modify spontaneous mobility and exploratory activity as indicated by the hole-board test. We can, thus, suppose that the effects observed in the passive avoidance test were not imputable to compromised behavioral paradigms. These results were of particular relevance since it has been observed that deletion of ryanodine receptor type 3 induces an increased speed of locomotion and a mild tendency to circular running (Balschun et al. 1999).

In conclusion, our results demonstrate that stimulation of RyRs ameliorates memory processes whereas a RyR blockade induces amnesia. In particular, knockdown of RyR2 and RyR3 induced a detrimental effect on memory functions indicating their fundamental role in memory processing. Conversely, RyR1 appears not to be endowed with a prominent role in the cellular events involved in learning and memory. Finally, present results indicate that a gene-specific cerebral RyR isoform level reduction by using an antisense strategy is compatible with animal life, is devoid of behavioral side effects, and represents a useful tool to investigate physiological and/or pathological central role of RyRmediated cellular events.

\section{Materials and Methods}

\section{Animals}

Male Swiss albino mice (23-30 g) from the Morini (San Polo d'Enza, Italy) breeding farm were used. Fifteen mice were housed per cage. The cages were placed in the experimental room $24 \mathrm{~h}$ before the test for acclimatization. The animals were fed a standard laboratory diet and tap water ad libitum and kept at $23 \pm 1{ }^{\circ} \mathrm{C}$ with a $12 \mathrm{~h} \mathrm{light/dark}$ cycle, light on at 7 a.m. All experiments were carried out in accordance with the European Communities Council Directive of 24 November 1986 (86/609/ EEC) for experimental animal care. All efforts were made to minimize the number of animals used and their suffering.

\section{Intracerebroventricular injection technique}

Intracerebroventricular administration was performed under ether anesthesia, as previously described (Galeotti et al. 2006). Briefly, during anesthesia, mice were grasped firmly by the loose skin behind the head. A $0.4-\mathrm{mm}$ external diameter hypodermic needle attached to a $10-\mu \mathrm{L}$ syringe was inserted perpendicularly through the skull and no more than $2 \mathrm{~mm}$ into the brain of the mouse, where $5 \mu \mathrm{L}$ were then administered. The injection site 
was $1 \mathrm{~mm}$ to the right or left from the midpoint on a line drawn through to the anterior base of the ears. Injections were performed into the right or left ventricle, randomly. To ascertain that the drugs were administered exactly into the cerebral ventricle, some mice (20\%) were injected with $5 \mu \mathrm{L}$ of diluted $1: 10$ India ink, and their brains examined macroscopically after sectioning. The accuracy of the injection technique was evaluated, and the percentage of correct injections was 95 .

\section{Passive-avoidance test}

The test was performed according to the step-through method described by Jarvik and Kopp (1967). The apparatus consisted of a two-compartment acrylic box with a lighted compartment connected to a darkened one by a guillotine door. As soon as the mouse entered the dark compartment, it received a punishing electrical shock $(0.5 \mathrm{~mA}, 1 \mathrm{sec})$. The latency times for entering the dark compartment were measured in the training test and after $24 \mathrm{~h}$ in the retention test. The maximum entry latency allowed in the training and retention sessions was, respectively, 60 and 180 sec. Between 15 and 22 mice were tested.

\section{Hole-board test}

The hole-board test was performed according to Galeotti et al. (2006). The test consisted of a 40-cm square plane with 16 flush mounted cylindrical holes $(3 \mathrm{~cm}$ diameter) distributed four by four in an equidistant, grid-like manner. Mice were placed on the center of the board one by one and allowed to move about freely for a period of $10 \mathrm{~min}$ each. Two electric eyes, crossing the plane from midpoint to midpoint of opposite sides, thus dividing the plane into four equal quadrants, automatically signaled the movement of the animal (counts in $5 \mathrm{~min}$ ) on the surface of the plane (locomotor activity). Miniature photoelectric cells, in each of the 16 holes, recorded (counts in $5 \mathrm{~min}$ ) the exploration of the holes (exploratory activity) by the mice. Twelve mice per group were tested.

\section{Rota-rod test}

The apparatus consisted of a base platform and a rotating rod with a diameter of $3 \mathrm{~cm}$ and a nonslippery surface. The rod was placed at a height of $15 \mathrm{~cm}$ from the base. The rod, $30 \mathrm{~cm}$ in length, was divided into 5 equal sections by 6 disks. Thus, up to five mice were tested simultaneously on the apparatus, with a rod-rotating speed of 16 revolutions per minute. The integrity of motor coordination was assessed on the basis of the number of falls from the rod in $30 \mathrm{~s}$ according to Vaught et al. (1985). Those mice scoring less than three and more than six falls in the pretest were rejected $(20 \%)$. The performance time was measured before (pretest) and 15, 30, and $45 \mathrm{~min}$ after the beginning of the test. Twelve mice per group were tested.

\section{Antisense oligonucleotides}

Phosphodiester oligonucleotides (ODNs) protected by terminal phosphorothioate double substitution (capped ODNs) against possible exonuclease-mediated degradation were purchased from Tib-Molbiol (Genoa, Italy). The sequences are the following: anti-

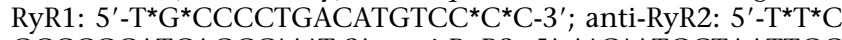
GCCCGCATCAGCC ${ }^{*} \mathrm{~A}^{*} \mathrm{~T}-3^{\prime}$; anti-RyR3: $5^{\prime}-\mathrm{A}^{*} \mathrm{G}^{*}$ ATGCTAATTGC $\mathrm{ATC}^{*} \mathrm{~T}^{*} \mathrm{C}-3^{\prime}$ (* indicates the phosphorothioate residues). A 18mer fully degenerated ODN (dODN), $5^{\prime}-\mathrm{N}^{\star} \mathrm{N}^{\star} \mathrm{NNNNNNNNNNN}$ $\mathrm{NNN}^{\star} \mathrm{N}^{\star} \mathrm{N}-3^{\prime}$ (where $\mathrm{N}$ is $\mathrm{G}$, or $\mathrm{C}$, or $\mathrm{A}$, or $\mathrm{T}$ ), was used as a control ODN. ODNs were vehiculated intracellularly by an artificial cationic lipid (DOTAP, Sigma) to enhance both uptake and stability. aODNs or dODNs were preincubated at $37^{\circ} \mathrm{C}$ for $30 \mathrm{~min}$ with 13 $\mu \mathrm{M}$ DOTAP and supplied to mice by i.c.v. injection of a $5-\mu \mathrm{L}$ solution once daily on days 1,2 , and 3 .

\section{Preparation of membranes}

Mouse brains were dissected to separate specific areas. Mouse hippocampus and cortex were homogenized in an homogenization buffer containing $25 \mathrm{mM}$ Tris- $\mathrm{HCl}$ at $\mathrm{pH} 7.5,25 \mathrm{mM} \mathrm{NaCl}$, $5 \mathrm{mM}$ EGTA, $2.5 \mathrm{mM}$ EDTA, $2 \mathrm{mM}$ NaPP, $4 \mathrm{mM}$ PNFF, $1 \mathrm{mM}$
$\mathrm{Na}_{3} \mathrm{VO}_{4}, 1 \mathrm{mM}$ PMSF, $20 \mu \mathrm{g} / \mathrm{mL}$ leupeptin, $50 \mu \mathrm{g} / \mathrm{mL}$ aprotinin, $0.1 \%$ SDS. The homogenate was centrifuged at $9000 \mathrm{~g}$ for $15 \mathrm{~min}$ at $4^{\circ} \mathrm{C}$, and the low-speed pellet was discarded. The microsomal membranes were obtained from the supernatant of the $9000 \mathrm{~g}$ spin by centrifugation at $100,000 \mathrm{~g}$ for $1 \mathrm{~h}$ at $4^{\circ} \mathrm{C}$. Microsomes were resuspended in homogenization buffer and stored at $-80^{\circ} \mathrm{C}$. Protein concentration of the microsomal fraction was quantified using a protein assay kit (Bio Rad Laboratories). Skeletal muscle microsomes were prepared from the posterior leg of mice. Cardiac microsomes were prepared from the entire heart, cleaned from large vessels.

\section{Western blot analysis}

Membrane homogenates $(100 \mu \mathrm{g})$ made from cerebellum, hippocampus and cortex regions of control and antisense-treated mice and membrane homogenates from skeletal and cardiac muscle were separated on 6\% SDS-PAGE and transferred onto nitrocellulose membranes $(180 \mathrm{~min}$ at $80 \mathrm{~V})$ using standard procedures. Membranes were blocked in PBST (PBS containing 0.1\% Tween) containing 5\% nonfat dry milk for $90 \mathrm{~min}$. Following washings, blots were incubated overnight at $4^{\circ} \mathrm{C}$ with specific antibodies against RyR1, RyR2, or RyR3 (1:3000 dilution), a kind gift of Professor Sorrentino (University of Siena, Italy). After being washed with PBS containing $0.1 \%$ Tween, the nitrocellulose membrane was incubated with goat anti-rabbit horseradish peroxidase-conjugated secondary antisera $(1: 10,000)$ and left for $1 \mathrm{~h}$ at room temperature. Blots were then extensively washed according to the manufacturer's instruction and developed using enhanced chemiluminescence detection system (Pierce). Exposition and developing time used was standardized for all the blots. Densitometric analysis of scanned images was performed on a Macintosh iMac computer using the public domain NIH Image program. Measurements in control samples were assigned a relative value of $100 \%$.

\section{Immunoprecipitation of RyR1, RyR2, RyR3}

Immunoprecipitation was carried out on $1 \mathrm{~mL}$ of microsomal fraction containing $200 \mu \mathrm{g}$ of proteins by incubation for $2 \mathrm{~h}$ at $4^{\circ} \mathrm{C}$ with $10 \mu \mathrm{g}$ of specific antibodies against RyR1, RyR2, or RyR3. All tubes then received $20 \mu \mathrm{L}$ of $25 \%$ (v/v) Protein GAgarose (Santa Cruz Biotechnology) and incubated for further 2 $\mathrm{h}$ at $4^{\circ} \mathrm{C}$. Pellets were collected by centrifugation at $1000 \mathrm{~g}$ for 5 min at $4^{\circ} \mathrm{C}$, washed three times with homogenization buffer. Pellets were finally resuspended in $40 \mu \mathrm{L}$ of electrophoresis sample buffer and boiled for $5 \mathrm{~min}$, and samples were processed by SDS-PAGE.

\section{Drug administration}

The following drugs were used: ryanodine, 4-chloro- $m$-cresol (Calbiochem); diphenhydramine hydrochloride, D-amphetamine hydrochloride (De Angeli, Rome, Italy); clonidine hydrochloride (Sigma). 4-Chloro- $m$-cresol (4-Cmc) was dissolved in $0.5 \%$ ethanol. All other drugs were dissolved in isotonic $(\mathrm{NaCl}$ $0.9 \%$ ) saline solution. Drug and ODNs concentrations were prepared in such a way that the necessary dose could be administered in a volume of $5 \mu \mathrm{L}$ by i.c.v. injection or $10 \mathrm{~mL} / \mathrm{kg}$ by subcutaneous (s.c.) or i.p. administration.

To perform time-course experiments, 4 -Cmc was administered 15,30 , or 60 min before and immediately after the training session, and ryanodine was administered 15 min before and immediately after the training session. In ryanodine time-course experiments, longer latencies from the training session $(30,60$ min) were not used, since, conversely to 4 -Cmc, it is endowed with a short lasting effect, as observed in previous behavioral experiments performed in our laboratory (Galeotti et al. 2004b, 2006). From time-course experiments the ideal time of administration of 4-Cmc (30 min before training) and ryanodine (immediately after training) was chosen to perform dose-response curves. The same administration times were used when 4-Cmc and ryanodine were coadministered. Clonidine and diphenhydramine, used as reference drugs, were administered, respectively, 70 min before and immediately after the training session. 
ODNs were i.c.v. injected once daily on days 1,2 , and 3 . Behavioral tests were performed on day $4,18 \mathrm{~h}$ after the last i.c.v. injection of ODNs, and on day 11 . Brain areas to conduct Western blotting experiments were collected on day $4,18 \mathrm{~h}$ after the last i.c.v injection and on day 11 .

\section{Statistical analysis}

All experimental results are given as the mean \pm SEM. Student's $t$-test or a two-way ANOVA followed by Bonferroni/Dunn posthoc test was used for statistical analysis; $P$-values of less than 0.05 were considered significant.

\section{Acknowledgments}

This work was supported by grants from the Ministero dell'Università e della Ricerca.

\section{References}

Balkowiec, A. and Katz, D.M. 2002. Cellular mechanisms regulating activity-dependent release of native brain-derived neurotrophic factor from hippocampal neurons. J. Neurosci. 22: 10399-10407.

Balschun, D., Wolfer, D.P., Bertocchini, F., Barone, V., Conti, A., Zuschratter, W., Missiaen, L., Lipp, H.-P., Frey, J.U., and Sorrentino, V. 1999. Deletion of the ryanodine receptor type 3 (RyR3) impairs forms of synaptic plasticity and spatial learning. EMBO J. 18: 5264-5273.

Breuer, A.C., Bond, M., and Atkinson, M.B. 1992. Fast axonal transport is modulated by altering trans-axolemmal calcium flux. Cell Calcium 13: $249-262$.

Campbell, L.W., Hao, S.Y., Thibault, O., Blalock, E.M., and Landfield, P.W. 1996. Aging changes in voltage-gated calcium currents in hippocampal CA1 neurons. I. Neurosci. 16: 6286-6295.

Disterhoft, J.F., Moyer Jr., J.R., and Thompson, L.T. 1994. The calcium rationale in aging and Alzheimer's disease. Evidence from an animal model of normal aging. Ann. N. Y. Acad. Sci. 747: 382-406.

Disterhoft, J.F., Thompson, L.T., Moyer Jr., J.R., and Mogul, D.J. 1996. Calcium dependent afterhyperpolarization and learning in young and aging hippocampus. Life Sci. 59: 413-420.

Disterhoft, J.F., Wu, W.W., and Ohno, M. 2004. Biophysical alterations of hippocampal pyramidal neurons in learning, ageing and Alzheimer's disease. Ageing Res. Rev. 3: 383-406.

Edwards, T.M. and Rickard, N.S. 2006. Pharmaco-behavioural evidence indicating a complex role for ryanodine receptor calcium release channels in memory processing for a passive avoidance task. Neurobiol. Learn. Mem. 86: 1-8.

Futatsugi, A., Kato, K., Ogura, H., Li, S.-T., Nagata, E., Kuwajima, G., Tanaka, K., Itohara, S., and Mikoshiba, K. 1999. Facilitation of NMDAR-independent LTP and spatial learning in mutant mice lacking ryanodine receptor type-3. Neuron 24: 701-713.

Galeotti, N., Bartolini, A., and Ghelardini, C. 2003. Diphenhydramine-induced amnesia is mediated by Gi-protein activation. Neuroscience 122: 471-478.

Galeotti, N., Bartolini, A., and Ghelardini, C. 2004a. Alpha-2 agonists induce amnesia though activation of the Gi-protein signalling pathway. Neuroscience 126: 451-460.

Galeotti, N., Bartolini, A., and Gheladini, C. 2004b. Role of intracellular calcium in acute thermal pain perception. Neuropharmacology 47: 935-944

Galeotti, N., Bartolini, A., and Ghelardini, C. 2006. Blockade of intracellular calcium release induces an antidepressant-like effect in the mouse forced swimming test. Neuropharmacology 50: 309-316.

Giannini, G., Conti, A., Mammarella, S., Scrobogna, M., and Sorrentino, V. 1995. The ryanodine receptor/calcium channel genes are widely and differentially expressed in murine brain and peripheral tissues. $J$. Cell Biol. 128: 893-904.

Gibson, G.E. and Peterson, C. 1987. Calcium and the aging nervous system. Neurobiol. Aging 8: 329-343.

He, X., Yang, F., Xie, Z., and Lu, B. 2000. Intracellular $\mathrm{Ca}^{2+}$ and $\mathrm{Ca}^{2+} /$ calmodulin-dependent kinase II mediate acute potentiation of neurotransmitter release by neurotrophin-3. J. Cell Biol. 149: $783-792$.

Hemond, P. and Jaffe, D.B. 2005. Caloric restriction prevents aging-associated changes in spike-mediated $\mathrm{Ca}^{2+}$ accumulation and the slow afterhyperpolarization in hippocampal CA1 pyramidal neurons. Neuroscience 135: 413-420.

Herrmann-Frank, A. and Varsanyi, M. 1993. Enhancement of $\mathrm{Ca}^{2+}$ release channel activity by phosphorylation of the skeletal muscle ryanodine receptor. FEBS Lett. 332: 237-242.

Ikemoto, T., Komazaki, S., Takeshima, H., Nishi, M., Noda, T., Iino, M., and Endo, M. 1997. Functional and morphological features of skeletal muscle from mutant mice lacking both type 1 and 3 ryanodine receptors. J. Physiol. 501: 305-312.

Jarvik, M. and Kopp, R. 1967. An improved passive avoidance learning situation. Psychol. Rep. 21: 221-224.

Kawai, T. and Watanabe, M. 1989. Effects of ryanodine on spike after-hyperpolarisation in sympathetic neurons of the rat superior cervical ganglion. Pflug. Arch. Eur. J. Physiol. 413: 470-475.

Khachaturian, Z.S. 1989. The role of calcium regulation in brain aging: Reexamination of a hypothesis. Aging (Milano) 1: 17-34.

Kouzu, Y., Moriya, T., Takeshima, H., Yoshioka, T., and Shibata, S. 2000 Mutant mice lacking ryanodine receptor type 3 exhibit deficits of contextual fear conditioning and activation of calcium/calmodulin-dependent protein kinase II in the hippocampus. Brain Res. Mol. Brain Res. 76: 142-150.

Kumar, A. and Foster, T.C. 2004. Enhanced long-term potentiation during aging is masked by processes involving intracellular calcium stores. J. Neurophysiol. 91: 2437-2444.

Landfield, P.W. 1987. 'Increased calcium-current' hypothesis of brain aging. Neurobiol. Aging 8: 346-347.

Landfield, P.W. 1996. Aging-related increase in hippocampal calcium channels. Life Sci. 59: 399-404.

Landfield, P.W. and Pitler, T.A. 1984. Prolonged Ca-dependent afterhyperpolarizations in hippocampal neurons of aged rats. Science 226: 1089-1092.

Landfield, P.W., Pitler, T.A., and Applegate, M.D. 1986. The effects of high $\mathrm{Mg}$ to- $\mathrm{Ca}^{2+}$ ratios on frequency potentiation in hippocampal slices of young and aged rats. J. Neurophysiol. 56: 797-811.

McPherson, P.S. and Campbell, K.P. 1993. The ryanodine receptor/Ca ${ }^{2+}$ release channel. J. Biol. Chem. 19: 13765-13768.

Moore, K.A., Cohen, A.S., Kao, J.P.Y., and Weinrerich, D. 1998. $\mathrm{Ca}^{2+}$-induced $\mathrm{Ca}^{2+}$ release mediates a slow post-spike hyperpolarization in rabbit vagal afferent neurons. J. Neurophysiol. 79: 688-694.

Mothet, J.-P., Fossier, P., Meunier, F.-M., Stinnakre, J., Tauc, L., and Baux, G. 1998. Cyclic ADP-ribose and calcium-induced calcium release regulate neurotransmitter release at a cholinergic synapse of Aplysia. J. Physiol. 507: 405-414.

Moyer Jr., J.R., Thompson, L.T., Black, J.P., and Disterhoft, J.F. 1992 Nimodipine increases excitability of rabbit CA1 pyramidal neurons in an age- and concentration-dependent manner. J. Neurophysiol. 68: $2100-2109$

Nishiyama, M., Hong, K., Mikoshiba, K., Poo, M.M., and Kato, K. 2000. Calcium stores regulate the polarity and input specificity of synaptic modification. Nature 408: 584-588.

Paschen, W., Doutheil, J., Gissel, C., and Treiman, M. 1996. Depletion of neuronal endoplasmic reticulum calcium stores by thapsigargin: Effect on protein synthesis. J. Neurochem. 67: 1735-1743.

Pitler, T.A. and Landfield, P.W. 1990. Aging-related prolongation of calcium spike duration in rat hippocampal slice neurons. Brain Res. 508: $1-6$.

Potier, B., Rascol, O., Jazat, F., Lamour, Y., and Dutar, P. 1992. Alterations in the properties of hippocampal pyramidal neurons in the aged rat. Neuroscience 48: 793-806.

Rossi, D. and Sorrentino, V. 2002. Molecular genetics of ryanodine receptors $\mathrm{Ca}^{2+}$-release channels. Cell Calcium 32: 307-319.

Sharp, A.H., McPherson, P.S., Dawson, T.D., Aoki, C., Campbell, K.P. and Snyder, S.H. 1993. Differential immunohistochemical localization of inositol 1,4,5-trisphosphate- and ryanodine-sensitive $\mathrm{Ca}^{2+}$ release channels in rat brain. J. Neurosci. 13: 3051-3063.

Simpson, P.B., Challiss, R.A.J., and Nahorski, S.R. 1995. Neuronal calcium stores: Activation and function. Trends Neurosci. 18: 299-305.

Stutzmann, G.E., Smith, I., Caccamo, A., Oddo, S., Laferla, F.M., and Parker, I. 2006. Enhanced ryanodine receptor recruitment contributes to $\mathrm{Ca}^{2+}$ disruptions in young, adult, and aged Alzheimer's disease mice. J. Neurosci. 26: 5180-5189.

Takeshima, H., Yamazawa, T., Ikemoto, T., Takekura, H., Nishi, M. Noda, T., and Iino, M. 1995. $\mathrm{Ca}^{2+}$-induce $\mathrm{Ca}^{2+}$ release in myocytes from dyspedic mice lacking the type-1 ryanodine receptors. EMBO J. 14: 2999-3006.

Takeshima, H., Komazaki, S., Hirose, K., Nishi, M., Noda, T., and Iino, M. 1998. Embryonic lethality and abnormal cardiac myocytes in mice lacking ryanodine receptor type 2. EMBO J. 17: 3309-3316.

Thibault, O., Porter, N.M., Chen, K.C., Blalock, E.M., Kaminker, P.G., Clodfelter, G.V., Brewer, L.D., and Landfield, P.W. 1998. Calcium dysregulation in neuronal aging and Alzheimer's disease: History and new directions. Cell Calcium 24: 417-433.

Thibault, O., Hadley, R., and Landfield, P.W. 2001. Elevated postsynaptic $\left[\mathrm{Ca}^{2+}\right] \mathrm{i}$ and L-type calcium channel activity in aged hippocampal neurons: Relationship to impaired synaptic plasticity. J. Neurosci. 21: 9744-9756. 
Toescu, E.C. and Verkhratsky, A. 2003. Neuronal ageing from an intraneuronal perspective: roles of endoplasmic reticulum and mitochondria. Cell Calcium 34: 311-323.

Tully, K. and Treistman, S.N. 2004. Distinct intracellular calcium profiles following influx through $\mathrm{N}$ - versus L-type calcium channels: Role of $\mathrm{Ca}^{2+}$-induce $\mathrm{Ca}^{2+}$ release. J. Neurophysiol. 92: 135-143.

Van de Vrede, Y., Fossier, P., Baux, G., Joels, M., and Chameau, P. 2007. Control of IsAHP in mouse hippocampus CA1 pyramidal neurons by RyR3-mediated calcium-induced calcium release. Pflug. Arch. Eur. J. Physiol. 455: 297-308.

Vaught, J., Pelley, K., Costa, L.G., Sether, P., and Enna, S.J. 1985. A comparison of the antinociceptive responses to GABA-receptor agonists THIP and baclofen. Neuropharmacology 24: 211-216.

Zalk, R., Lehnart, S.E., and Mark, A.R. 2007. Modulation of the ryanodine receptor and intracellular calcium. Annu. Rev. Biochem. 76: $367-385$.

Zhang, L., Pennefather, P., Velumian, A., Tymianski, M., Charlton, M and Carlen, P.L. 1995. Potentiation of a slow $\mathrm{Ca}^{2+}$-dependent $\mathrm{K}+$ current by intracellular $\mathrm{Ca}^{2+}$ chelators in hippocampal CA1 neurons of rat brain slices. J. Neurophysiol. 74: 2225-2241.

Zhao, W., Meiri, N., Xu, H., Cavallaro, S., Quattrone, A., Zhang, L., and Alkon, D.L. 2000. Spatial learning induced changes in expression of the ryanodine type II receptor in the rat hippocampus. FASEB $J$. 14: $290-300$.

Received January 25, 2008; accepted in revised form March 3, 2008. 


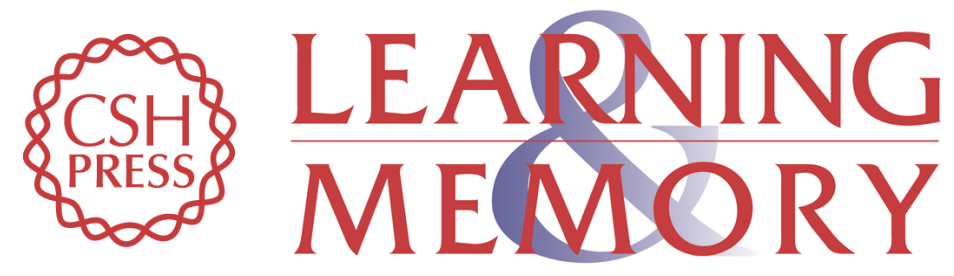

\section{Different involvement of type 1, 2, and 3 ryanodine receptors in memory processes}

Nicoletta Galeotti, Alessandro Quattrone, Elisa Vivoli, et al.

Learn. Mem. 2008, 15:

Access the most recent version at doi:10.1101//m.929008

References This article cites 51 articles, 9 of which can be accessed free at:

http://learnmem.cshlp.org/content/15/5/315.full.html\#ref-list-1

License

Email Alerting Receive free email alerts when new articles cite this article - sign up in the box at the Service top right corner of the article or click here. 